J. Dairy Sci. 92:5907-5916

doi:10.3168/jds.2009-2520

(c) American Dairy Science Association, 2009.

\title{
Physicochemical, microbial, and sensory properties of yogurt supplemented with nanopowdered chitosan during storage
}

\author{
M. H. Seo, S. Y. Lee, Y. H. Chang, and H. S. Kwak ${ }^{1}$ \\ Department of Food Science and Technology, Sejong University, Seoul 143-747, Korea
}

\begin{abstract}
This study was carried out to determine the possibility of adding nanopowdered chitosan (NPC) into cholesterol-reduced yogurt to improve the functionality of yogurt and the effects of adding NPC on the physicochemical, microbial, and sensory properties of the products during storage. The $\mathrm{pH}$ values and mean lactic acid bacteria counts of NPC-added $(0.3$ to $\sim 0.7 \%$, wt/ vol) and cholesterol-reduced yogurt ranged from 4.19 to 4.41 and from $4.75 \times 10^{8}$ to $9.70 \times 10^{8} \mathrm{cfu} / \mathrm{mL}$, respectively, when stored at $4^{\circ} \mathrm{C}$ for $20 \mathrm{~d}$, thereby indicating a possibility of prolonging the shelf life of yogurt. In color, the $\mathrm{a}^{*}$ and $\mathrm{b}^{*}$ values for cholesterol-reduced yogurt were not significantly influenced by the addition of NPC ( 0.1 to $\sim 0.7 \%$, wt/vol); however, the $\mathrm{L}^{*}$ values significantly decreased with the addition of the greatest concentration $(0.7 \%, \mathrm{wt} / \mathrm{vol})$ of NPC at $0-\mathrm{d}$ storage. The sensory test revealed that the astringency scores significantly increased at 0 - $d$ storage when the greatest concentration $(0.7 \%$, wt $/ \mathrm{vol})$ of NPC was added into cholesterol-reduced yogurt. Based on the data obtained from the current study, it is concluded that concentrations ( 0.3 to $\sim 0.5 \%$, vol $/ \mathrm{vol}$ ) of NPC could be used to produce an NPC-added and cholesterol-reduced yogurt without significantly adverse effects on the physicochemical, microbial, and sensory properties.
\end{abstract}

Key words: cholesterol-reduced yogurt, nanopowdered chitosan, cross-linked $\beta$-cyclodextrin, shelf life

\section{INTRODUCTION}

Chitosan, the main derivative of chitin, is a linear aminopolysaccharide composed primarily of repeating units of $\beta$ - $(1 \rightarrow 4) 2$-amino-2-deoxy-D-glucose (Dglucosamine) (Pillai et al., 2009; Shu et al., 2009). The hypoglycemic effects of chitosan have been reported in previous studies (Kondo et al., 2000; Hayashi and Ito, 2002; Lee et al., 2003; Yao et al., 2008; Kumar et al., 2009). According to Kumar et al. (2009), the control

Received June 29, 2009.

Accepted September 1, 2009.

${ }^{1}$ Corresponding author: kwakhs@sejong.ac.kr group (no supplement of chitosan) had elevated blood glucose levels, whereas the levels of blood glucose were decreased in ob/ob mice groups fed chitosan $(20 \mathrm{mg} /$ $\mathrm{kg}$ per day) for $28 \mathrm{~d}$. Lee et al. (2003) studied the antidiabetic effect of chitosan oligosaccharide in neonatal streptozotocin-induced non-insulin-dependent diabetes mellitus rats and found that the plasma glucose level was decreased by about $19 \%$ in diabetic rats after treatment with $0.3 \%$ chitosan oligosaccharide. Lee et al. (2003) also reported that chitosan oligosaccharide can be used as an antidiabetic agent because it elevates glucose tolerance and insulin secretion and reduces triglyceride levels.

Nanosizing is an emerging technique used for enhancing physical and biological properties including solubility and stability (Rasenack and Muller, 2004; Park et al., 2007). According to Park et al. (2007), nanocalcium supplementation in milk might be an effective way to improve bone calcium metabolism for ovariectomized rats. In our animal study investigating the cholesterollowering effect of nanopowdered chitosan (NPC) in rats, it was shown that NPC reduced total cholesterol by $46.6 \%$, as compared with the commercially powdered chitosan (CPC), which reduced total cholesterol by $18.6 \%$ (J. H. Park; unpublished data).

In recent years, many different food ingredients, including evening primrose oil (Lee et al., 2007), $\beta$-glucan (Gee et al., 2007; Sahan et al., 2008), and green and black teas (Jaziri et al., 2009) have been included in yogurt formulations to improve the nutritional value. Moreover, reducing cholesterol in yogurt can be another great way to enhance the health benefits. Lee et al. (2007) reported that the cholesterol from milk (the major ingredient for the manufacture of yogurt) can be effectively removed by $\beta$-cyclodextrin $(\boldsymbol{\beta}-\mathbf{C D})$, and they employed the cholesterol-reduced milk for the production of cholesterol-reduced yogurt. They noted that the physicochemical and sensory properties of cholesterol-reduced yogurt were not remarkably different from those of the control (without the removal of cholesterol).

So-called healthy foods, especially those with nutraceutical properties, are in great demand in our healthconscious society. Nutraceutical yogurt could be a good 
vehicle in this respect if nutraceutical ingredients, such as NPC, were used to fortify yogurt and the cholesterol was removed from yogurt. However, there is no report in the literature on the production of an NPC-added and cholesterol-reduced yogurt. Therefore, the objectives of the current study were to investigate (1) the possibility of adding NPC into cholesterol-reduced yogurt and (2) the effects of adding NPC on the physicochemical, microbial, and sensory properties of the products during storage.

\section{MATERIALS AND METHODS}

\section{Materials}

Commercial milk (3.6\% milk fat) was purchased from Seoul Dairy Co-op (Seoul, Korea). Commercially powdered chitosan was obtained from Samsung Chitopia (Seoul, Korea) and ground to NPC by the dry milling method in Apexel Co. (Pohang, Korea) at room temperature. Commercial $\beta-\mathrm{CD}$ (purity 99.1\%) was purchased from Nihon Shokuhin Cako Co. Ltd. (Osaka, Japan). Cholesterol and $5 \alpha$-cholestane were purchased from Sigma Chemical Co. (St. Louis, MO), and all solvents were of gas-chromatographic grade.

\section{Particle Size Analysis}

Commercially powdered chitosan or NPC was mounted on a brass stub (10 $\mathrm{mm}$ in diameter) using 2-sided adhesive tape. The stub surface was gently blown to remove unattached chitosan powders using a hand-held blower. The specimens were then made electrically conductive by coating under an argon atmosphere with a thin layer (approximately $30 \mathrm{~nm}$ in thickness) of platinum-palatium (8:2). The specimens were examined using a scanning electron microscope (Hitachi S-4700, Tokyo, Japan) operated at an accelerating voltage of $15 \mathrm{kV}$. The particle size of NPC was determined by Delsa Nano particle size analyzer (Beckman Coulter, Fullerton, CA).

\section{Preparation of Cross-linked $\beta$-Cyclodextrin}

A $100-\mathrm{g}$ sample of $\beta-\mathrm{CD}$ was dissolved in $80 \mathrm{~mL}$ of distilled water and placed in a stirrer at room temperature with constant agitation for $2 \mathrm{~h}$. Adipic acid $(2 \mathrm{~g})$ was then incorporated into the $\beta$-CD solution, and the $\mathrm{pH}$ was adjusted to 10 with $1 \mathrm{~N} \mathrm{NaOH}$. The $\beta$-CD solution was stirred at room temperature for 90 min and then readjusted to $\mathrm{pH} 5$ with $0.5 \%$ acetic acid. The $\beta$-CD was recovered by filtering through Whatman No. 2 filter paper and washing 3 times with $150 \mathrm{~mL}$ of distilled water. The product was dried at $60^{\circ} \mathrm{C}$ in a
Lab-Line mechanical convection oven (O-Sung Scientific Co., Seoul, Korea) for $20 \mathrm{~h}$ and passed through a 100-mesh sieve (Han et al., 2005).

\section{Manufacture of CPC- or NPC-Added and Cholesterol-Reduced Yogurt}

To manufacture CPC- or NPC-added and cholesterol-reduced yogurt, cholesterol was first removed as follows: $500 \mathrm{~mL}$ of milk was placed in a $1,000-\mathrm{mL}$ beaker, and $1.0 \%$ (wt/vol) $\beta$-CD was added. The mixture was stirred at $800 \mathrm{rpm}$ with a blender (Tops, Misung
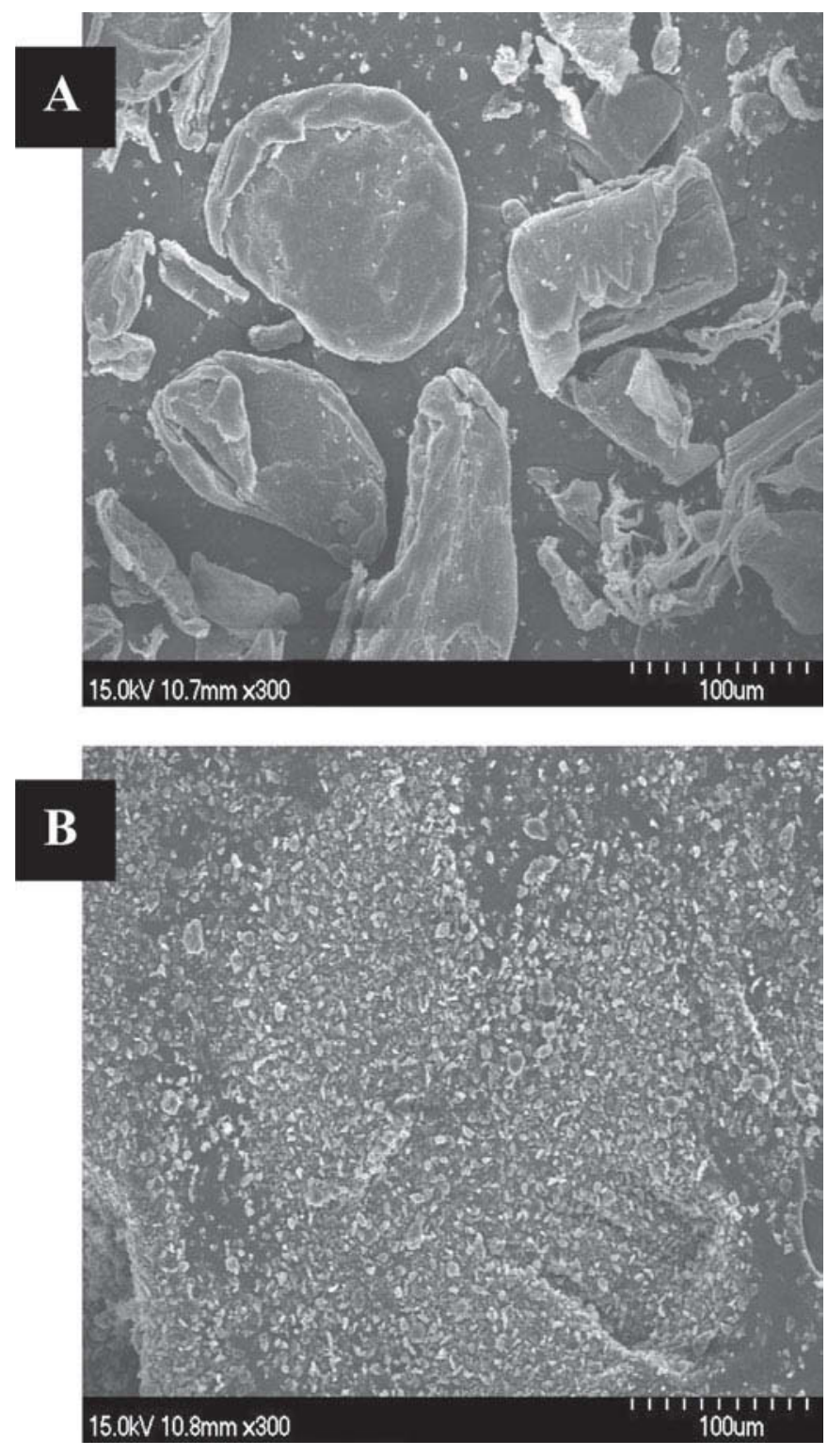

Figure 1. Scanning electron microscope images for commercially powdered chitosan (A) and nanopowdered chitosan (B). 


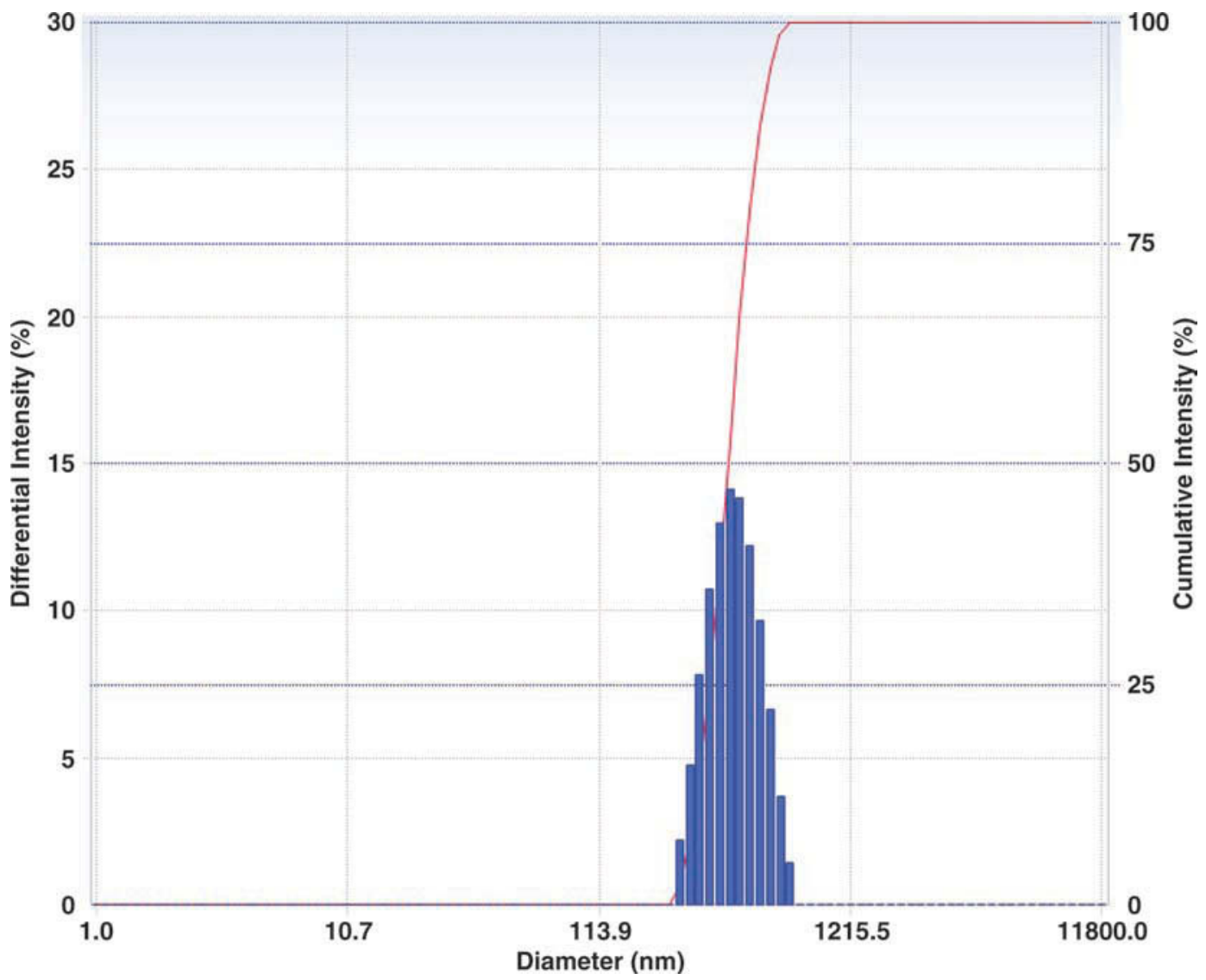

Figure 2. Particle size analysis of nanopowdered chitosan. Color version available in the online PDF.

Co., Seoul, Korea) in a temperature-controlled water bath at $10^{\circ} \mathrm{C}$ for $10 \mathrm{~min}$. The mixture was centrifuged (HMR-220IV, Hanil Industrial Co., Seoul, Korea) at room temperature at $166 \times g$ for $10 \mathrm{~min}$, and the supernatant, the cholesterol-removed milk, was collected for yogurt manufacture.

Nonfat dry milk $(3.7 \%$, wt $/ \mathrm{vol})$ and pectin $(0.2 \%$, wt/vol, Kanto Chemical, Tokyo, Japan) were added into the cholesterol-reduced milk and then homogenized at $50^{\circ} \mathrm{C}$ under 1,000 psi in a single-stage homogenizer (HC 5000, Micro Fluidics Corp., Newton, MA). The homogenized milk was heated at $90^{\circ} \mathrm{C}$ for $10 \mathrm{~min}$ and cooled to approximately 42 to $43^{\circ} \mathrm{C}$. A $0.004 \%$ (wt/ vol) commercial starter culture (Chr. Hansen Pty. Ltd., Bayswater, Australia) in freeze-dried direct-to-vat set form containing Lactobacillus bulgaricus and Streptococcus thermophilus was added and fermented at $43^{\circ} \mathrm{C}$ for $6 \mathrm{~h}$. The cholesterol-reduced yogurt samples were combined with different concentrations $(0.1,0.3,0.5$, and $0.7 \%$, wt/vol) of $\mathrm{CPC}$ or NPC and stabilized at $10^{\circ} \mathrm{C}$ for $24 \mathrm{~h}$. After stabilizing, each yogurt sample was stored for $0,5,10,15$, and $20 \mathrm{~d}$ at $4^{\circ} \mathrm{C}$ in a refrigerator to evaluate the physicochemical and sensory properties. Each batch of yogurt making was done in triplicate.

\section{Extraction and Determination of Cholesterol}

For the extraction of cholesterol from yogurt, $1 \mathrm{~g}$ of a yogurt sample was placed in a screw-capped glass tube $(15 \mathrm{~mm} \times 180 \mathrm{~mm})$, and $1 \mathrm{~mL}$ of $5 \alpha$-cholestane $(1 \mathrm{mg} /$ $\mathrm{mL}$ ) was added as an internal standard. The sample was saponified at $60^{\circ} \mathrm{C}$ for 30 min with $5 \mathrm{~mL}$ of $2 M$ ethanolic potassium hydroxide solution (Adams et al., 1986). The process was repeated 4 times. The hexane layers were transferred to a round-bottomed flask and dried under vacuum. The extract was redissolved in 1 $\mathrm{mL}$ of hexane and stored at $-20^{\circ} \mathrm{C}$ until analysis.

The cholesterol was determined on a silica fused capillary column (HP-5, $30 \mathrm{~m} \times 0.32 \mathrm{~mm}$ i.d. $\times$ $0.25 \mu \mathrm{m}$ thickness) using a Hewlett-Packard 5890A gas chromatograph (Palo Alto, CA) equipped with a flame-ionization detector. The injector and detector temperatures were 270 and $300^{\circ} \mathrm{C}$, respectively. The oven temperatures were programmed from 200 to $300^{\circ} \mathrm{C}$ 


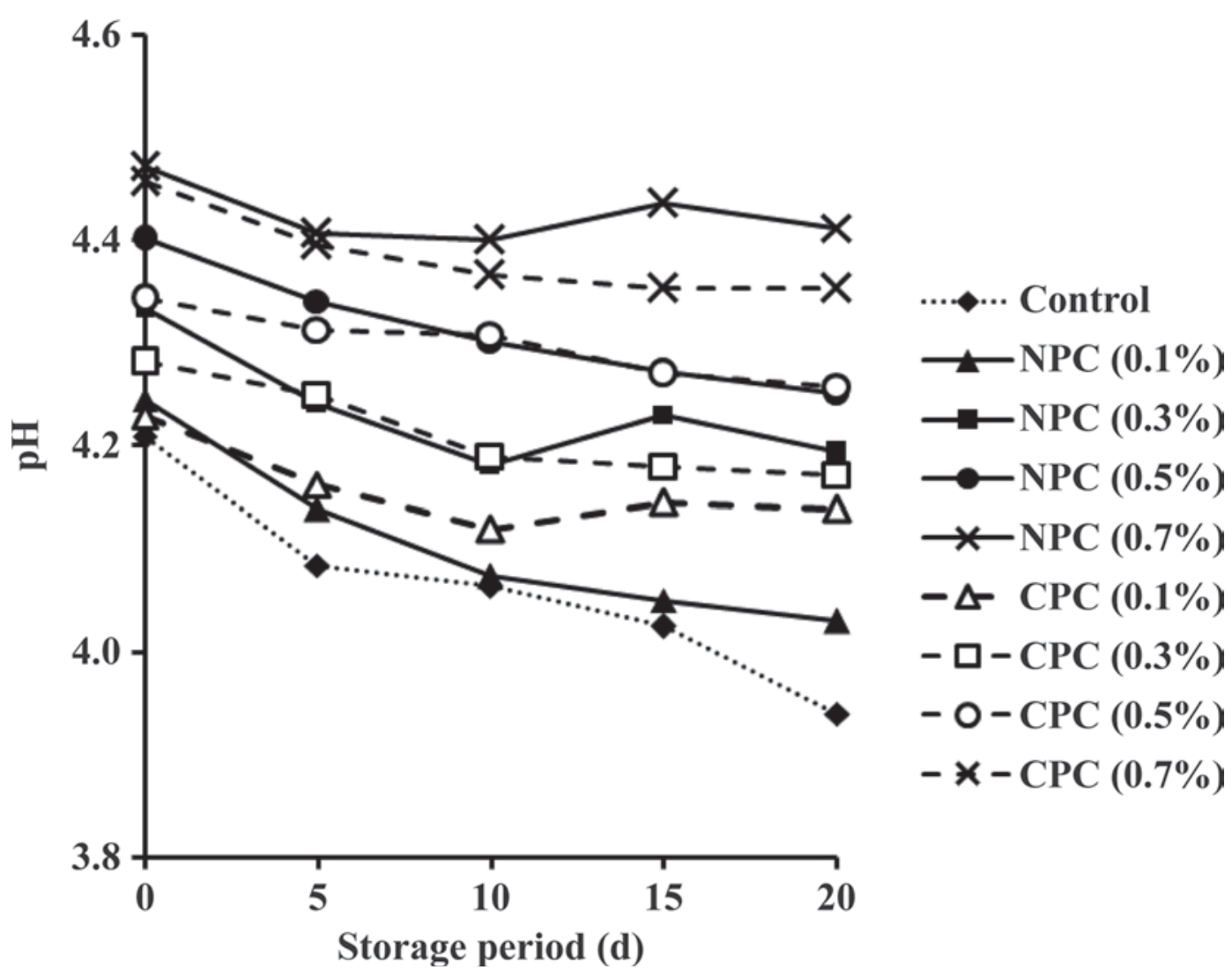

Figure 3. Changes in pH in nanopowdered chitosan (NPC)- or commercially powdered chitosan (CPC)-added and cholesterol-reduced yogurt stored at $4^{\circ} \mathrm{C}$ for $20 \mathrm{~d}$. Milk used was treated with $1 \%$ cross-linked $\beta$-cyclodextrin for all samples. At $0 \mathrm{~d}$, yogurt had been stabilized for 24 h.

at $10^{\circ} \mathrm{C} / \mathrm{min}$ and held for $20 \mathrm{~min}$. Nitrogen was used as a carrier gas at a flow rate of $2 \mathrm{~mL} / \mathrm{min}$ with a split ratio of 1:50. Quantification of cholesterol was done by comparing the peak areas with the response of an internal standard.

The percentage of cholesterol reduction was calculated as follows: cholesterol reduction $(\%)=100-($ amount of cholesterol in $\beta$-CD-treated yogurt $\times 100$ /amount of cholesterol in the control). Cholesterol determination for the control was averaged with each batch of treatments.

\section{Chemical Analyses}

The $\mathrm{pH}$ values of each yogurt sample were measured using a pH meter (Orion 900A, Boston, MA). The titratable acidity values of each yogurt sample were determined after mixing the yogurt sample with $10 \mathrm{~mL}$ of hot distilled water $\left(90^{\circ} \mathrm{C}\right)$ and titrating with $0.1 \mathrm{~N}$ $\mathrm{NaOH}$ containing $0.5 \%$ phenolphthalein as an indicator to an end point of faint pink color. All samples were measured in triplicate.

\section{Viscosity}

The viscosity of yogurt samples $(100 \mathrm{~mL})$ was measured after mixing of the sample for 5 min at room temperature using a Brookfield Viscometer (Model LVDV I+, Version 3.0, Stonington, MA) with a spindle No. 2 at $60 \mathrm{rpm}$. All samples were measured in triplicate.

\section{Color}

Color values of each yogurt sample were investigated using a colorimeter (CR210, Minolta, Tokyo, Japan) after calibrating its original value with a standard plate $(\mathrm{X}=97.83, \mathrm{Y}=81.58, \mathrm{Z}=91.51)$. Measured $\mathrm{L}^{*}$, $\mathrm{a}^{*}$, and $\mathrm{b}^{*}$ values were used as indicators of lightness, redness, and yellowness, respectively. All samples were measured in triplicate.

\section{Lactic Acid Bacteria}

de Man, Rogosa, Sharpe agar (Difco Laboratories, Detroit, MI) combined with $0.004 \%$ bromophenol blue 


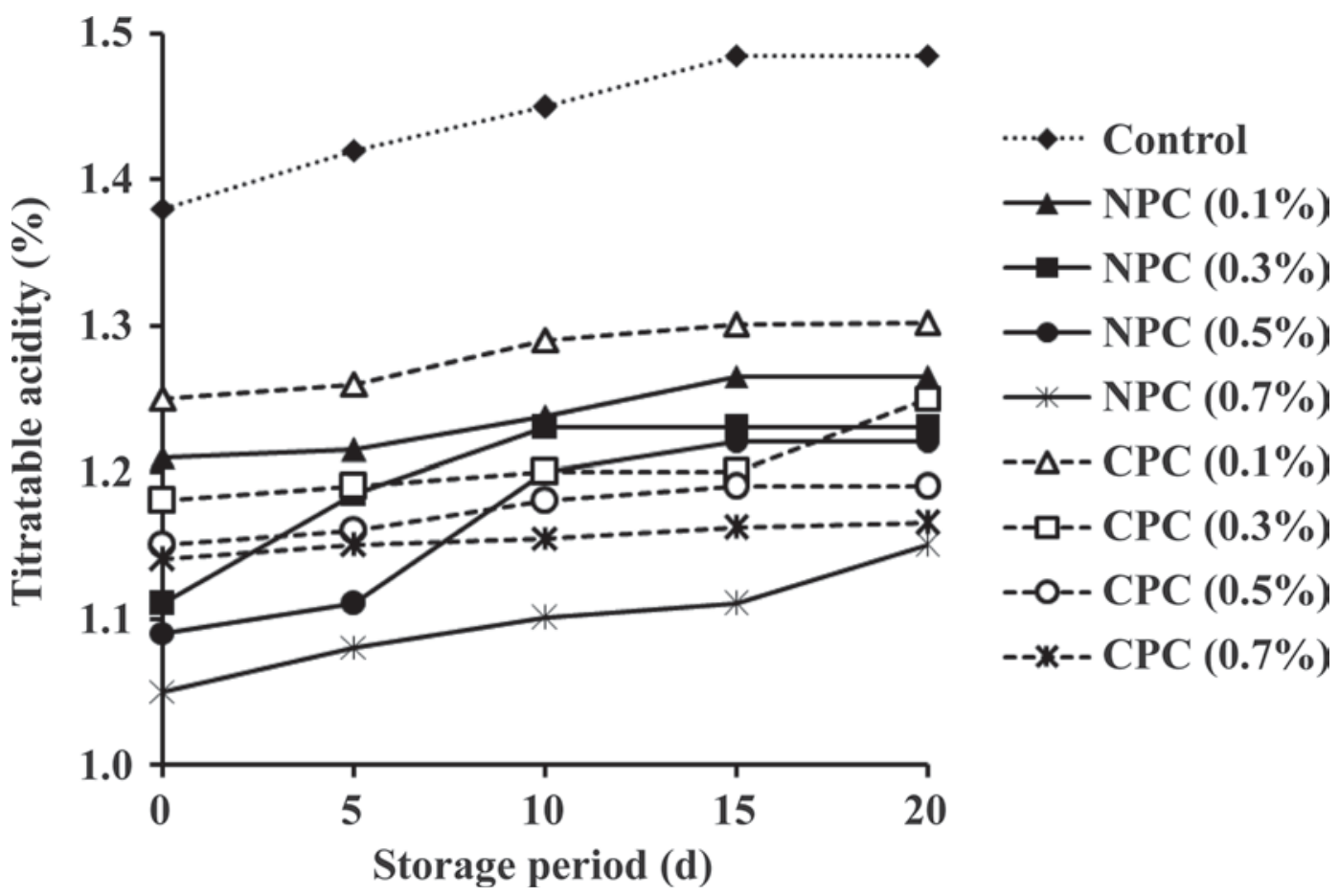

Figure 4. Changes in titratable acidity in nanopowdered chitosan (NPC)- or commercially powdered chitosan (CPC)-added and cholesterolreduced yogurt stored at $4^{\circ} \mathrm{C}$ for $20 \mathrm{~d}$. Milk used was treated with $1 \%$ cross-linked $\beta$-cyclodextrin for all samples. At $0 \mathrm{~d}$, yogurt had been stabilized for $24 \mathrm{~h}$.

(Sigma Chemical Co.) was used for L. bulgaricus and Strep. thermophilus counting. One milliliter of yogurt samples was diluted with $9 \mathrm{~mL}$ of sterile peptone and water diluents. Subsequent dilutions of each sample were plated in triplicate and incubated at $37^{\circ} \mathrm{C}$ for 48 h.

\section{Sensory Analysis}

Eight trained sensory panelists evaluated randomly coded yogurt samples. The appearance, flavor, taste, texture, and overall acceptability were investigated on a 7 -point scale $(1=$ very weak, $4=$ moderate, $7=$ very strong).

\section{Statistical Analysis}

All statistical analyses were performed using SAS version 9.0 (SAS Institute Inc., Cary, NC). An ANOVA was performed using the general linear models procedure to determine significant differences among the samples. Means were compared by using Fisher's least significant difference procedure. Significance was defined at the $5 \%$ level.

\section{RESULTS AND DISCUSSION}

\section{Particle Size Analysis}

The morphology of CPC and NPC was observed by scanning electron microscope, as shown in Figure 1. The scanning electron microscope images demonstrated that the particle size of CPC apparently decreased during the manufacture of NPC. The average particle sizes of CPC and NPC measured were about $150 \mu \mathrm{m}$ (as measured by scanning electron microscope) and about $562 \mathrm{~nm}$ in diameter (as measured by the particle size analyzer), respectively (Figures 1 and 2).

\section{Cholesterol Removal}

The cholesterol content of the control yogurt (without the supplementation of CPC or NPC) was $13.5 \mathrm{mg} / 100$ $\mathrm{g}$, and the cholesterol reduction reached $93.1 \%$ with $1 \%$ $\beta-\mathrm{CD}$ treatment (data not shown). This finding was in agreement with our previous study using powdered $\beta$-CD in which we reached a $93.5 \%$ cholesterol reduction in yogurt (Lee et al., 2007). Furthermore, the efficient removal of more than $90 \%$ of cholesterol by using cross- 
Table 1. Changes of lactic acid bacteria ${ }^{1}(\mathrm{cfu} / \mathrm{mL})$ in nanopowdered chitosan (NPC)- or commercially powdered chitosan $(\mathrm{CPC})$-added and cholesterol-reduced yogurt ${ }^{2}$ stored at $4^{\circ} \mathrm{C}$ for $20 \mathrm{~d}$

\begin{tabular}{lccccc}
\hline & \multicolumn{5}{c}{ Storage period (d) } \\
\cline { 2 - 6 } $\begin{array}{l}\text { Concentration of } \\
\text { sample (\%, wt/vol) }\end{array}$ & 0 & 5 & 10 & 15 & 20 \\
\hline Control & $9.15 \times 10^{10 \mathrm{a}}$ & $1.45 \times 10^{10 \mathrm{a}}$ & $4.40 \times 10^{9 \mathrm{a}}$ & $1.68 \times 10^{9 \mathrm{a}}$ & $1.70 \times 10^{9 \mathrm{a}}$ \\
NPC (0.1) & $7.00 \times 10^{10 \mathrm{~b}}$ & $2.45 \times 10^{9 \mathrm{c}}$ & $1.29 \times 10^{9 \mathrm{~b}}$ & $1.02 \times 10^{9 \mathrm{~b}}$ & $9.90 \times 10^{8 \mathrm{~b}}$ \\
NPC (0.3) & $2.49 \times 10^{10 \mathrm{c}}$ & $2.16 \times 10^{9 \mathrm{c}}$ & $1.85 \times 10^{9 \mathrm{~b}}$ & $9.75 \times 10^{8 \mathrm{c}}$ & $9.70 \times 10^{8 \mathrm{~b}}$ \\
NPC (0.5) & $2.45 \times 10^{10 \mathrm{c}}$ & $1.90 \times 10^{9 \mathrm{~d}}$ & $1.09 \times 10^{9 \mathrm{~b}}$ & $6.95 \times 10^{8 \mathrm{c}}$ & $6.25 \times 10^{8 \mathrm{c}}$ \\
NPC (0.7) & $1.85 \times 10^{10 \mathrm{~d}}$ & $1.50 \times 10^{9 \mathrm{~d}}$ & $9.20 \times 10^{8 \mathrm{c}}$ & $4.85 \times 10^{8 \mathrm{~d}}$ & $4.75 \times 10^{8 \mathrm{~d}}$ \\
CPC (0.1) & $6.34 \times 10^{1 \mathrm{~b}}$ & $5.25 \times 10^{9 \mathrm{~b}}$ & $1.38 \times 10^{9 \mathrm{~b}}$ & $1.19 \times 10^{9 \mathrm{~b}}$ & $9.00 \times 10^{8 \mathrm{~b}}$ \\
CPC (0.3) & $2.25 \times 10^{10 \mathrm{c}}$ & $2.08 \times 10^{9 \mathrm{c}}$ & $1.31 \times 10^{9 \mathrm{~b}}$ & $8.05 \times 10^{8 \mathrm{c}}$ & $7.45 \times 10^{8 \mathrm{c}}$ \\
CPC (0.5) & $1.18 \times 10^{10 \mathrm{~d}}$ & $7.40 \times 10^{8 \mathrm{e}}$ & $8.75 \times 10^{8 \mathrm{c}}$ & $5.25 \times 10^{8 \mathrm{~d}}$ & $4.05 \times 10^{8 \mathrm{~d}}$ \\
CPC (0.7) & $1.08 \times 10^{10 \mathrm{~d}}$ & $6.50 \times 10^{8 \mathrm{e}}$ & $3.00 \times 10^{8 \mathrm{~d}}$ & $1.35 \times 10^{8 \mathrm{e}}$ & $2.50 \times 10^{8 \mathrm{e}}$ \\
\hline
\end{tabular}

${ }^{\mathrm{a} e}$ Values with different superscript letters within the same column differ significantly $(P<0.05)$.

${ }^{1}$ The mixture of Lactobacillus bulgaricus and Streptococcus thermophilus.

${ }^{2}$ Milk used was treated with $1 \%$ cross-linked $\beta$-cyclodextrin for all samples.

linked $\beta-C D$ has been found in other dairy products (Kim et al., 2005, 2006, 2008; Han et al., 2007).

\section{Changes in $\mathrm{pH}$ and Titratable Acidity}

Figure 3 shows the changes of $\mathrm{pH}$ values in $\mathrm{CPC}$ or NPC-added and cholesterol-reduced yogurt stored at $4^{\circ} \mathrm{C}$ for $20 \mathrm{~d}$. The $\mathrm{pH}$ values increased when $\mathrm{CPC}$ or NPC $(0.3$ to $\sim 0.7 \%$, wt/vol) was incorporated into the cholesterol-reduced yogurt samples during storage. It was also found that at 0 -d storage, elevating the concentrations of both NPC and CPC in the cholesterol-reduced yogurt samples from 0.3 to $0.7 \%$ (wt/vol) resulted in an increase in the $\mathrm{pH}$ values from 4.33 to 4.47 and from 4.28 to 4.46 , respectively.

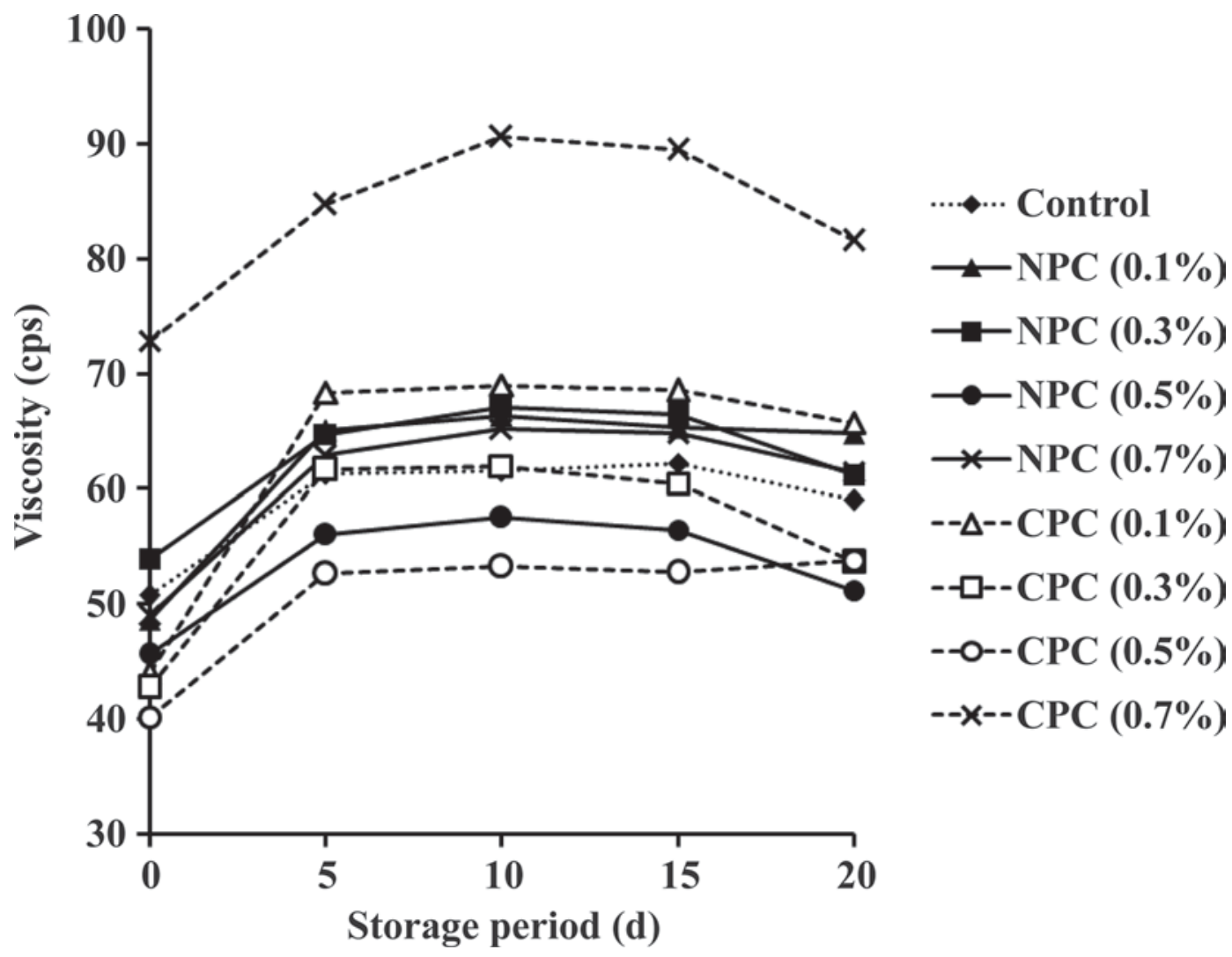

Figure 5. Changes in viscosity for nanopowdered chitosan (NPC)- or commercially powdered chitosan (CPC)-added and cholesterol-reduced yogurt stored at $4^{\circ} \mathrm{C}$ for $20 \mathrm{~d}$. Milk used was treated with $1 \%$ cross-linked $\beta$-cyclodextrin for all samples. At $0 \mathrm{~d}$, yogurt had been stabilized for $24 \mathrm{~h}$. 
Table 2. Changes of color for nanopowdered chitosan (NPC)- or commercially powdered chitosan (CPC)-added and cholesterol-reduced yogurt ${ }^{1}$ stored at $4^{\circ} \mathrm{C}$ for $20 \mathrm{~d}$

\begin{tabular}{|c|c|c|c|c|c|c|c|c|c|c|c|c|c|c|c|}
\hline \multirow{2}{*}{$\begin{array}{l}\text { Concentration } \\
\text { of sample } \\
(\%, \mathrm{wt} / \mathrm{vol})\end{array}$} & \multicolumn{15}{|c|}{ Storage period (d) } \\
\hline & \multicolumn{3}{|c|}{0} & \multicolumn{3}{|c|}{5} & \multicolumn{3}{|c|}{10} & \multicolumn{3}{|c|}{15} & \multicolumn{3}{|c|}{20} \\
\hline$\overline{\text { Control }}$ & $88.96^{\mathrm{a}}$ & $3.04^{\mathrm{a}}$ & $5.81^{\mathrm{a}}$ & $89.00^{\mathrm{a}}$ & $3.05^{\mathrm{ab}}$ & $6.01^{\mathrm{a}}$ & $88.92^{\mathrm{a}}$ & $3.07^{\mathrm{abc}}$ & $6.14^{\mathrm{b}}$ & $89.88^{\mathrm{a}}$ & $3.20^{\mathrm{a}}$ & $6.84^{\mathrm{b}}$ & $88.88^{\mathrm{a}}$ & $3.27^{\mathrm{ab}}$ & $7.06^{\mathrm{b}}$ \\
\hline NPC $(0.1)$ & $88.46^{\mathrm{a}}$ & $2.88^{\mathrm{ab}}$ & $6.20^{\mathrm{a}}$ & $87.95^{\mathrm{a}}$ & $3.08^{\mathrm{a}}$ & $6.29^{\mathrm{a}}$ & $88.62^{\mathrm{ab}}$ & $3.02^{\text {abc }}$ & $6.34^{\mathrm{ab}}$ & $89.52^{\mathrm{ab}}$ & $3.19^{\mathrm{a}}$ & $6.37^{\mathrm{c}}$ & $87.51^{\mathrm{d}}$ & $3.29^{\mathrm{a}}$ & $6.41^{\mathrm{c}}$ \\
\hline NPC $(0.3)$ & $88.86^{\mathrm{a}}$ & $2.81^{\mathrm{ab}}$ & $6.29^{\mathrm{a}}$ & $87.40^{\mathrm{b}}$ & $3.05^{\mathrm{ab}}$ & $6.33^{\mathrm{a}}$ & $88.82^{\mathrm{ab}}$ & $3.08^{\mathrm{abc}}$ & $6.40^{\mathrm{ab}}$ & $89.11^{\mathrm{ab}}$ & $3.20^{\mathrm{a}}$ & $6.42^{\mathrm{c}}$ & $86.58^{\mathrm{e}}$ & $3.23^{\mathrm{ab}}$ & $6.46^{\mathrm{c}}$ \\
\hline CPC (0.1) & $88.94^{\mathrm{a}}$ & $2.88^{\mathrm{ab}}$ & $6.04^{\mathrm{a}}$ & $88.66^{\mathrm{a}}$ & $2.87^{\mathrm{ab}}$ & $6.12^{\mathrm{a}}$ & $88.67^{\mathrm{ab}}$ & $2.85^{\mathrm{ab}}$ & $6.39^{\mathrm{ab}}$ & $87.77^{\mathrm{c}}$ & $2.91^{\mathrm{a}}$ & $6.89^{\mathrm{ab}}$ & $88.15^{\mathrm{bc}}$ & $3.02^{\text {bcd }}$ & $7.30^{\mathrm{ab}}$ \\
\hline CPC (0.3) & $88.92^{\mathrm{a}}$ & $2.81^{\mathrm{ab}}$ & $6.20^{\mathrm{a}}$ & $88.64^{\mathrm{a}}$ & $2.82^{\mathrm{ab}}$ & $6.28^{\mathrm{a}}$ & $88.59^{\mathrm{b}}$ & $2.88^{\text {abc }}$ & $6.43^{\mathrm{ab}}$ & $87.86^{\mathrm{c}}$ & $2.94^{\mathrm{a}}$ & $6.91^{\mathrm{ab}}$ & $88.24^{\mathrm{b}}$ & $2.91^{\mathrm{d}}$ & $7.33^{\mathrm{ab}}$ \\
\hline CPC (0.5) & $88.77^{\mathrm{a}}$ & $2.74^{\mathrm{b}}$ & $6.34^{\mathrm{a}}$ & $88.70^{\mathrm{a}}$ & $2.75^{\mathrm{ab}}$ & $6.44^{\mathrm{a}}$ & $88.67^{\mathrm{ab}}$ & $2.88^{\text {abc }}$ & $6.67^{\mathrm{a}}$ & $87.11^{\mathrm{c}}$ & $2.92^{\mathrm{a}}$ & $6.95^{\mathrm{ab}}$ & $87.85^{\mathrm{c}}$ & $2.93^{\mathrm{cd}}$ & $7.35^{\mathrm{ab}}$ \\
\hline CPC (0.7) & $88.70^{\mathrm{a}}$ & $2.65^{\mathrm{b}}$ & $6.48^{\mathrm{a}}$ & $88.56^{\mathrm{a}}$ & $2.74^{\mathrm{ab}}$ & $6.52^{\mathrm{a}}$ & $88.61^{\mathrm{ab}}$ & $2.79^{\mathrm{c}}$ & $6.70^{\mathrm{a}}$ & $85.21^{\mathrm{d}}$ & $2.86^{\mathrm{a}}$ & $7.13^{\mathrm{a}}$ & $86.58^{\mathrm{e}}$ & $2.94^{\mathrm{cd}}$ & $7.43^{\mathrm{a}}$ \\
\hline
\end{tabular}

${ }^{\mathrm{a}-\mathrm{f}}$ Values with different superscripts within the same column differ significantly $(P<0.05)$.

${ }^{1}$ Milk used was treated with $1 \%$ cross-linked $\beta$-cyclodextrin for all samples.

The normal $\mathrm{pH}$ of commercial yogurt products ranged from 4.0 to 4.4 (Kroger, 1976; Sahan et al., 2008). In the current study, increasing the storage period from 0 to $20 \mathrm{~d}$ considerably decreased the $\mathrm{pH}$ values for the control from 4.21 to 3.94, indicating that the yogurt quality remarkably decreased after $20 \mathrm{~d}$ of storage. However, it was observed that the $\mathrm{pH}$ values of CPCor NPC-added and cholesterol-reduced yogurt samples were not dramatically changed during storage for 20 $\mathrm{d}$, except for the $0.1 \%$ NPC-added and cholesterolreduced yogurt sample, which exhibited the reduction of $\mathrm{pH}$ values from 4.25 to 4.03 during 20 -d storage, demonstrating that the quality of cholesterol-reduced yogurt samples including NPC (0.3 to $\sim 0.7 \%$, wt/vol) was not remarkably varied during 20-d storage. Based on the results (regarding the $\mathrm{pH}$ changes of NPC-added and cholesterol-reduced yogurt) obtained from the current study, it was speculated that adding NPC (0.3 to $\sim 0.7 \%$, wt $/ \mathrm{vol})$ into the cholesterol-reduced yogurt could extend the shelf life.

Adding CPC or NPC (0.1 to $\sim 0.7 \%$, wt/vol) into the cholesterol-reduced yogurt samples decreased the values of titratable acidity (Figure 4). The values of titratable acidity for all the samples studied were slightly increased when stored at $4^{\circ} \mathrm{C}$ for $20 \mathrm{~d}$. The findings (regarding the decrease in the $\mathrm{pH}$ values and the increase in the titratable acidity values for yogurt samples during 20 -d storage at $4^{\circ} \mathrm{C}$ ) obtained from the current study were consistent with Lee et al. (2007), who showed that $\mathrm{pH}$ decreased and titratable acidity increased when evening primrose oil-enriched and cholesterol-reduced yogurt samples were stored at $4^{\circ} \mathrm{C}$ for $15 \mathrm{~d}$.

\section{Lactic Acid Bacteria}

The changes of L. bulgaricus and Strep. thermophilus in CPC- or NPC-added and cholesterol-reduced yogurt samples stored at $4^{\circ} \mathrm{C}$ for $20 \mathrm{~d}$ are shown in Table 1 . At 0 -d storage, the mean microbial counts of the control were greater than those of CPC- or NPC-added (0.1 to $\sim 0.7 \%$, wt $/ \mathrm{vol}$ ) and cholesterol-reduced yogurt samples. Moreover, increasing the concentrations of $\mathrm{CPC}$ and NPC from 0.1 to $0.7 \%$ (wt/vol) at 0 -d storage resulted in a reduction of the mean microbial counts from 6.34 $\times 10^{10}$ to $1.08 \times 10^{10} \mathrm{cfu} / \mathrm{mL}$ and from $7.00 \times 10^{10}$ to $1.85 \times 10^{10} \mathrm{cfu} / \mathrm{mL}$, respectively. The findings could be explained by the fact that chitosan has antimicrobial effects (Kendra and Hadwiger, 1984; Sudarshan et al., 1992; No et al., 2002; Qi et al., 2004). No et al. (2002) noted that chitosan markedly inhibited the growth of gram-positive bacteria such as Staphylococcus. aureus, Lactobacillus bulgaricus, Lactobacillus plantarum and Lactobacillus brevis. Qi et al. (2004) showed that the antimicrobial activity of chitosan nanoparticles (mean diameter $=40 \mathrm{~nm}$ ) was significantly greater than that of non-nanopowdered chitosan. In our preliminary test, the reduction of lactic acid bacteria in NPC- or CPCadded and cholesterol-reduced yogurt samples was found because of the antimicrobial activity of chitosan; therefore, we incorporated the greater concentration $(0.004 \%, \mathrm{wt} / \mathrm{vol})$ of starter culture into the cholesterolreduced yogurt to maintain the quality of yogurt during storage, instead of the concentration $0.002 \%$ (wt/ vol), which is recommended by the manufacturer of the starter culture.

\section{Viscosity and Color}

The viscosity values of all the samples studied increased sharply during 5-d storage and were almost constant until 15-d storage. After 20-d storage, the viscosity values were slightly decreased (Figure 5). Increasing values of viscosity were also observed in concentrated (Abu-Jdayil and Mohameed, 2002; Sahan et 
Table 3. Sensory characteristics ${ }^{1}$ for nanopowdered chitosan (NPC)- or commercially powdered chitosan (CPC)-added and cholesterol-reduced yogurt ${ }^{2}$ stored at $4^{\circ} \mathrm{C}$ for $20 \mathrm{~d}$

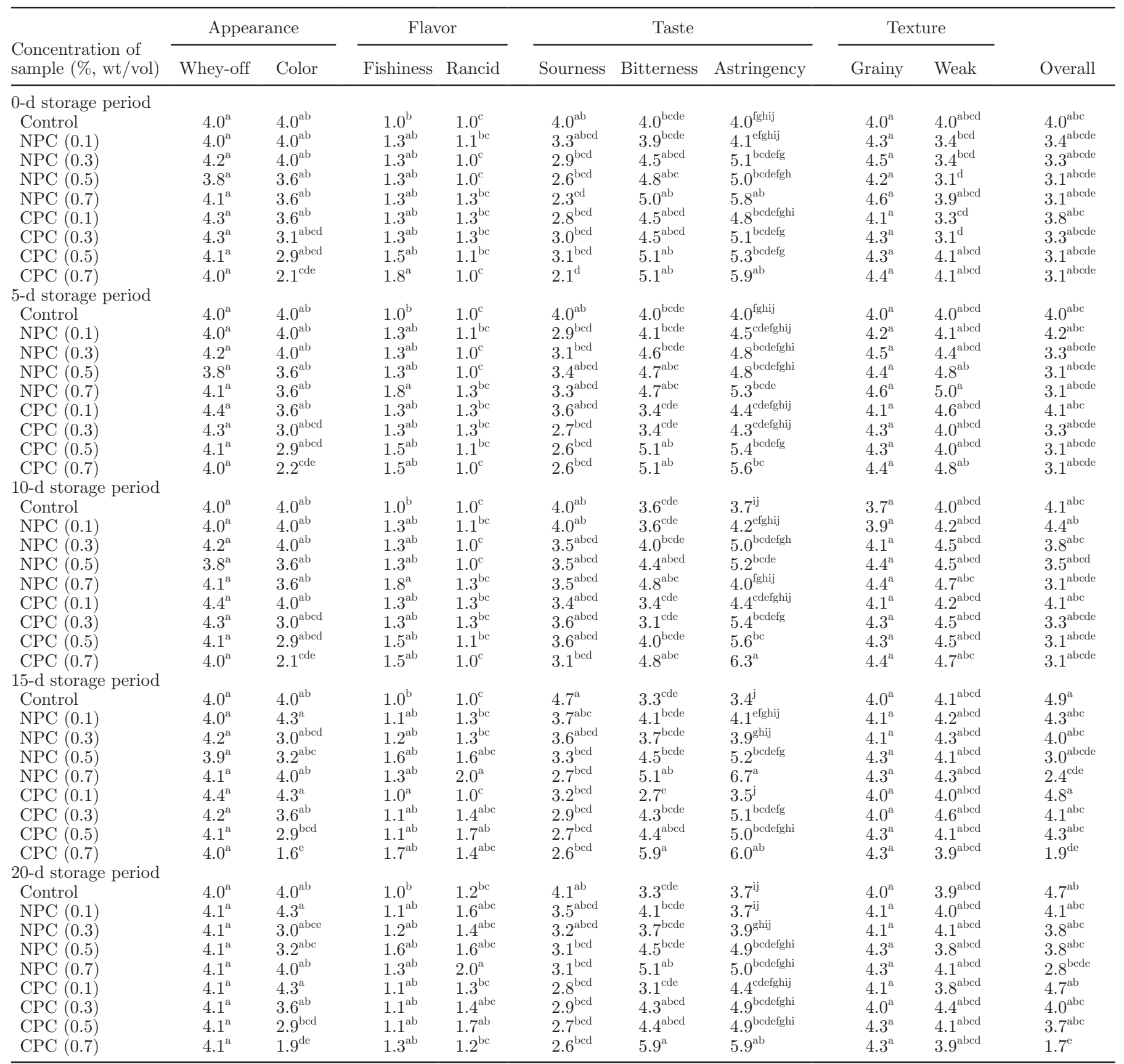

${ }^{\mathrm{a}-\mathrm{j}}$ Values with different superscripts within the same column differ significantly $(P<0.05)$.

${ }^{1}$ The scale of appearance, flavor, taste, texture, and color scores: $1=$ very week, $4=$ moderate, $7=$ very strong.

${ }^{2}$ Milk used was treated with $1 \%$ cross-linked $\beta$-cyclodextrin for all samples.

al., 2008) and nonfat plain yogurt (Isleten and KaragulYuceer, 2006). According to Sahan et al. (2008), the increase in viscosity values for nonfat yogurt during 15 $\mathrm{d}$ of storage can be associated with the rearrangement of protein molecules.

The changes of color for CPC- or NPC-added and cholesterol-reduced yogurt samples stored at $4^{\circ} \mathrm{C}$ for 20 $\mathrm{d}$ are presented in Table 2 . The $\mathrm{L}^{*}$ values for all the samples studied were not considerably changed during storage. However, the $\mathrm{a}^{*}$ and $\mathrm{b}^{*}$ values for the control sample increased from 3.04 to 3.27 and from 5.81 to 7.06, respectively, when the storage period increased from 0 to $20 \mathrm{~d}$. The $0.7 \%$ (wt/vol) NPC sample was the only sample that had a significantly lower $\mathrm{L}^{*}$ value 
at 0 -d storage as compared with the control. The $\mathrm{a}^{*}$ values of $\mathrm{CPC}(0.5$ and $0.7 \%$, wt/vol) and $\mathrm{NPC}(0.7 \%$, wt/vol) at 0-d storage were significantly decreased as compared with the control. The $\mathrm{b}^{*}$ values for the yogurt samples at 0-d storage were not significantly affected by the addition of CPC or NPC.

\section{Sensory Evaluation}

The sensory properties of CPC- or NPC-added and cholesterol-reduced yogurt samples stored at $4^{\circ} \mathrm{C}$ for $20 \mathrm{~d}$ are listed in Table 3. The whey-off scores for the cholesterol-reduced yogurt samples were not significantly influenced by prolonged storage $(20 \mathrm{~d})$ or the addition of CPC or NPC. The color score at $0-\mathrm{d}$ storage was significantly decreased when the greatest concentration $(0.7 \%$, wt $/ \mathrm{vol})$ of $\mathrm{CPC}$ was added into the cholesterol-reduced yogurt samples, probably because of the original yellow color of chitosan. Only the cholesterol-reduced yogurt sample including CPC $(0.7 \%$, wt $/ \mathrm{vol})$ exhibited a significantly greater fishiness score at 0-d storage, as compared with the control. The rancid scores for the yogurt samples at 0-d storage were not significantly affected by the addition of CPC or NPC. In the taste test, it was revealed that adding CPC or NPC (0.7\%, wt/vol) into cholesterol-reduced yogurt samples caused a significant decrease in the sourness scores and a significant increase in the astringency scores at 0 -d storage. The greater astringency scores for yogurt samples that include the chitosan powders $(0.7 \%$, wt $/ \mathrm{vol})$ were probably the result of the original astringent flavor of the original chitosan powder. According to the texture test, the grainy and weak scores for the cholesterol-reduced yogurt samples at 0-d storage were not significantly affected by the addition of CPC or NPC. Finally, adding CPC or NPC into the cholesterol-reduced yogurt samples did not significantly influence the overall scores at d 0, 5, and 10 .

Based on all the sensory data obtained from the current study, it is suggested that concentrations $(0.1$ to $\sim 0.5 \%$, wt/vol) of NPC could be used for the production of NPC-added and cholesterol-reduced yogurt without the deterioration of sensory properties.

\section{CONCLUSIONS}

The current study was designed to develop an NPCadded and cholesterol-reduced yogurt and to evaluate the effects of adding NPC on the physicochemical, microbial, and sensory properties of the final products during storage. The data on the $\mathrm{pH}$, titratable acidity, microbial, color, and sensory analysis obtained from the current study indicated that concentrations $(0.3$ to $0.5 \%$ ) of NPC could be applicable in NPC-added and cholesterol-reduced yogurt development. The production of yogurt that incorporates NPC can broaden the utilization of chitosan, and the products can be regarded as possible health-promoting nutraceutical foods.

\section{ACKNOWLEDGMENTS}

This study was supported by the Ministry for Food, Agriculture, Forestry and Fisheries Project in Seoul, Republic of Korea.

\section{REFERENCES}

Abu-Jdayil, B., and H. Mohameed. 2002. Experimental and modeling studies of the flow properties of concentrated yogurt as affected by storage time. J. Food Eng. 52:359-365.

Adams, M. L., D. M. Sullivan, R. L. Smith, and E. F. Richer. 1986. Evaluation of direct saponification method in determination of cholesterol in meats. J. Assoc. Anal. Chem. 69:844-846.

Gee, V. L., T. Vasanthan, and F. Temelli. 2007. Viscosity of model yogurt systems enriched with barley $\beta$-glucan as influenced by starter cultures. Int. Dairy J. 17:1083-1088.

Han, E. M., S. H. Kim, J. Aha, and H. S. Kwak. 2007. Optimizing cholesterol removal from cream using $\beta$-cyclodextrin cross-linked with adipic acid. Int. J. Dairy Technol. 60:31-36.

Han, E. M., S. H. Kim, J. Ahn, and H. S. Kwak. 2005. Cholesterol removal from homogenized milk with crosslinked $\beta$-cyclodextrin by adipic acid. Asian-australas. J. Anim. Sci. 18:1794-1799.

Hayashi, K., and M. Ito. 2002. Antidiabetic action of low molecular weight chitosan in genetically obese diabetic KK- $\mathrm{A}^{\mathrm{y}}$ mice. Biol. Pharm. Bull. 25:188-192.

Isleten, M., and Y. Karagul-Yuceer. 2006. Effects of dried dairy ingredients on physical and sensory properties of nonfat yogurt. J. Dairy Sci. 89:2865-2872.

Jaziri, I., M. Ben Slama, H. Mhadhbi, M. C. Urdaci, and M. Hamdi. 2009. Effect of green and black teas (Camellia sinensis L.) on the characteristic microflora of yogurt during fermentation and refrigerated storage. Food Chem. 112:614-620.

Kendra, D. F., and L. A. Hadwiger. 1984. Characterization of the smallest chitosan oligomer that is maximally antifungal to Fusarium solani and elicits pisatin formation in Pisum sativum. Exp. Mycol. 8:276-281.

Kim, H. Y., H. Y. Bae, and H. S. Kwak. 2008. Development of cholesterol-reduced Blue cheese made by crosslinked $\beta$-cyclodextrin. Milchwissenschaft. 63:53-56.

Kim, J. J., T. H. Jung, J. Ahn, and H. S. Kwak. 2006. Properties of cholesterol-reduced butter made with $\beta$-cyclodextrin and added evening primrose oil and phytosterols. J. Dairy Sci. 89:45034510.

Kim, S. H., E. M. Han, J. Ahn, and H. S. Kwak. 2005. Effect of crosslinked $\beta$-cyclodextrin on quality of cholesterol-reduced cream cheese. Asian-australas. J. Anim. Sci. 18:584-589.

Kondo, Y., A. Nakatani, K. Hayash, and M. Ito. 2000. Low molecular weight chitosan prevents the progression of low dose streptozotocininduced slowly progressive diabetes mellitus in mice. Biol. Pharm. Bull. 23:1458-1464.

Kroger, M. 1976. Quality of yogurt. J. Dairy Sci. 59:344-350.

Kumar, S. G., M. H. Rahman, S. H. Lee, H. S. Hwang, H. A. Kim, and J. W. Yun. 2009. Plasma proteome analysis for anti-obesity and anti-diabetic potentials of chitosan oligosaccharides in ob/ob mice. Proteomics 9:2149-2162.

Lee, H. W., Y. S. Park, J. W. Choi, S. Y. Yi, and W. S. Shin. 2003 Antidiabetic effects of chitosan oligosaccharides in neonatal streptozotocin-induced noninsulin-dependent diabetes mellitus in rats. Biol. Pharm. Bull. 26:1100-1103.

Lee, S. J., J. H. Hwang, S. Lee, J. Ahn, and H. S. Kwak. 2007. Property changes and cholesterol-lowering effects in evening primrose oil- 
enriched and cholesterol-reduced yogurt. Int. J. Dairy Technol. 60:22-30.

No, H. K., N. Y. Park, S. H. Lee, and S. P. Meyers. 2002. Antibacterial activity of chitosans and chitosan oligomers with different molecular weights. Int. J. Food Microbiol. 74:65-72.

Park, H. S., B. J. Jeon, J. Ahn, and H. S. Kwak. 2007. Effects of nanocalcium supplemented milk on bone calcium metabolism in ovariectomized rats. Asian-australas. J. Anim. Sci. 20:12661271

Pillai, C. K. S., W. Paul, and C. P. Sharma. 2009. Chitin and chitosan polymers: Chemistry, solubility and fiber formation. Prog. Polym. Sci. 34:641-678.

Qi, L., X. Zirong, X. Jiang, C. Hu, and X. Zou. 2004. Preparation and antibacterial activity of chitosan nanoparticles. Carbohydr. Res. $339: 2693-2700$.

Rasenack, N., and B. W. Muller. 2004. Micron-size drug particles: Common and novel micronization techniques. Pharm. Dev. Technol. 9:1-13.
Sahan, N., K. Yasar, and A. A. Hayaloglu. 2008. Physical, chemical and flavor quality of non-fat yogurt as affected by a $\beta$-glucan hydrocolloidal composite during storage. Food Hydrocoll. 22:1291-1297.

Shu, S., X. Zhang, D. Teng, Z. Wang, and C. Li. 2009. Polyelectrolyte nanoparticles based on water-soluble chitosan-poly (L-aspartic acid)-polyethylene glycol for controlled protein release. Carbohydr. Res. 344:1197-1204

Sudarshan, N. R., D. G. Hoover, and D. Knorr. 1992. Antibacterial action of chitosan. Food Biotechnol. 6:257-272.

Yao, H. T., S. Y. Huang, and M. T. Chiang. 2008. A comparative study on hypoglycemic and hypocholesterolemic effects of high and low molecular weight chitosan in streptozotocin-induced diabetic rats. Food Chem. Toxicol. 46:1525-1534. 